\title{
An unusual presentation of non-specific cystic degeneration of craniofacial fibrous dysplasia: a case report and review of literature
}

\author{
Inseok Hong ${ }^{1,2}$, Dong Cheol Kang ${ }^{1,2}$, Dae-Ho Leem ${ }^{1,2}$, Jin-A Baek ${ }^{1,2}$ and Seung-O Ko ${ }^{1,2^{*}}$ (1)
}

\begin{abstract}
Background: Fibrous dysplasia (FD) is a rare, sporadic, and benign congenital condition in which normal cancellous bone is replaced by fibro-osseous tissue with immature osteogenesis. FD localized in the cranial and facial bones is called craniofacial fibrous dysplasia (CFD). Cystic degeneration in CFD cases is rare; cystic degeneration appearing in both the maxilla and the mandible FD lesion is even rarer. The aim of this article was to report a case of fibrous dysplasia of the mandible and maxilla complicated by nonspecific cystic degeneration.
\end{abstract}

Case presentation: A 30-year-old woman presented with a rare case of non-specific cystic degeneration in a mandible and maxilla FD lesion that occurred 11 years after surgery. She was diagnosed with polyostotic CFD and underwent maxillary and mandibular bone contouring. Cyst enucleation under general anesthesia was performed in the mandibular region due to pain and discomfort.

Conclusions: In cases involving non-aggressive and non-invasive FD cystic degeneration in focal areas, conservative treatment is recommended. However, if cystic degeneration of FD develops rapidly and causes discomfort, pain, or dysfunction, surgical treatment should be considered.

Keywords: Craniofacial fibrous dysplasia, Cystic degeneration, Cyst enucleation, Fibrous dysplasia, Mandible, Maxilla, Polyostotic fibrous dysplasia

\section{Background}

Fibrous dysplasia (FD) is a benign disorder characterized by the replacement of normal bone tissue with proliferative fibrous connective tissues [1]. Somatic mutations in the Gs-alpha gene on chromosome 20 can lead to endocrine tumors, FD, and McCune-Albright syndrome (MAS) [2]. FD occurs in two forms: the monostotic form affecting one bone (approximately $70 \%$ of cases), and the polyostotic form affecting at least two bones

\footnotetext{
* Correspondence: omfskso@jbnu.ac.kr

'Department of Oral and Maxillofacial Surgery, School of Dentistry, Chonbuk National University Dental Hospital, 20, Geonji-ro, Deokjin-gu, Jeonju-si, Jeollabuk-do, Republic of Korea

${ }^{2}$ Research Institute of Clinical Medicine-Biomedical Research Institute, Chonbuk National University Hospital, 20, Geonji-ro, Deokjin-gu, Jeonju-si, Jeollabuk-do, Republic of Korea
}

\section{Springer Open}

(c) The Author(s). 2020 Open Access This article is licensed under a Creative Commons Attribution 4.0 International License, which permits use, sharing, adaptation, distribution and reproduction in any medium or format, as long as you give appropriate credit to the original author(s) and the source, provide a link to the Creative Commons licence, and indicate if changes were made. The images or other third party material in this article are included in the article's Creative Commons licence, unless indicated otherwise in a credit line to the material. If material is not included in the article's Creative Commons licence and your intended use is not permitted by statutory regulation or exceeds the permitted use, you will need to obtain permission directly from the copyright holder. To view a copy of this licence, visit http://creativecommons.org/licenses/by/4.0/. cranial and facial bones is called craniofacial fibrous dysplasia (CFD). The prevalence of polyostotic and monostotic CFD is $71-91 \%$ and $10-29 \%$, respectively $[4,5]$. In the jaw bone, FD is approximately twofold more prevalent in the maxilla and usually occurs unilaterally [1].

Non-epithelial-lined cysts sometimes occur in association with various benign and malignant bone lesions, including FD, giant cell tumors, chondroblastoma, ossifying fibroma, benign osteoblastoma, cemento-osseous dysplasia, fibrous histiocytoma, fibrosarcoma, and osteosarcoma. These cysts show various patterns and can appear as aneurysmal bone cysts, simple bone cysts, or non-specific cystic degenerations [6]. 
Cystic degeneration in CFD cases is rare; cystic degeneration appearing in both the maxilla and the mandible is even rarer. A PubMed search from 1946-2019 (using the search terms "fibrous dysplasia" [Ti] OR "McCuneAlbright" [Ti] OR "Jaffe-Lichtenstein" [Ti] OR "Mazabraud" [Ti] AND (cyst [Ti] OR cystic [Ti]) initially identified 78 articles. After screening and manual review, a total of seven articles on the occurrence of cystic degeneration in maxillary or mandibular FD were identified [6-12].

\section{Case presentation}

In November 2018, a 30-year-old woman presented to the Department of Oral and Maxillofacial Surgery of Chonbuk National University Hospital with a complaint of pain and swelling in the left mandible that had appeared 10 days earlier. Eleven years ago, she was diagnosed with CFD (Fig. 1a, b) and had received bone contouring in the left zygomaticomaxillary complex and left mandibular region under general anesthesia in the same department (Fig. 2a, b). Postoperative healing was uneventful and 18 months postoperatively, there was no specific problem with the lesion (Fig. 1c). The patient had subsequently been lost to follow-up until November 2018.

A review of medical history prior to November 2018 confirmed that she had not received any dental treatment or suffered trauma to the painful left mandible area in recent months. Her pain intensity rating was 4 points on the numeric pain rating scale. Clinical examination revealed slight swelling in the left midface and left submandibular areas, along with bony expansion from the posterior of the left mandibular angle to the inferior aspect of the \#34 tooth. The patient did not complain of hypoesthesia or pain when pressure was applied to the area. During an intraoral observation, the swelling was found from the distal aspect of \#33 to the mesial vestibule area in relation to \#36. During the endodontic examination, tooth mobility and percussion reactions were not observed in \#34, 35, and 36. Moreover, the electric pulp test (EPT) showed normal response from \#34, 35, and 36. No evidence of gum inflammation, such as periodontal pockets or gingival sulcus swelling and bleeding, was found during the periodontal examination. Furthermore, in the panoramic view, the dental origin with the possible infection source was not observed (Fig. 1d).

A well-defined multilocular radiolucent lesion in the left posterior mandibular region was identified on the panoramic radiograph, and the location of the lesion overlapped with the existing FD. In addition, amorphous calcified foci were observed inside the lesion (Fig. 1d).

Cone-beam computed tomography (CBCT) showed an expansive bone lesion with a ground-glass appearance spanning the left frontotemporal bone, crista galli, orbital wall, ethmoid bone, sphenoid bone, zygoma, pterygoid plate, and maxilla regions (Fig. 3a). An ill-defined (partially well-defined) irregular osteolytic lesion was observed inside the left mandibular lesion, and cortical thinning, buccolingual expansion, and cortical destruction were also identified (Fig. 3a).

A decision to perform a marsupialization procedure was made to first control edema and pain, and second to take a biopsy. The marsupialization procedure was performed after an intraoral incisional biopsy of the area surrounding the \#34 and \#35 teeth, followed by root canal treatments on these teeth. The biopsy results revealed some evidence of chronic inflammation and that the lesion may be a bony lesion with inflammatory reaction rather than FD. During a 3-week observational period, the size of the lesion was unchanged according to clinical and radiological findings (Fig. 3b). Eventually, we decided that cyst enucleation under general anesthesia should be performed in the mandibular region. However, in the maxilla region, since there was no pain or discomfort, we decided to follow-up without any surgical treatment.

\section{Surgical note}

At the time of surgery, the lesion had expanded from the inferior aspect of the \#34 tooth to the mesial root of the \#36 tooth, with fibrotic tissue scattered within the lesion. Subsequently, the soft tissue lesion was removed by cyst enucleation. The perilesional bone and the roots of the \#34, 35 teeth, and the mesial root of the \#36 tooth were ground. Electrocautery was applied to the interior of the lesion and a thorough curettage was performed (Fig. 4).

\section{Pathological note}

The lesions removed by cyst enucleation were sent for tissue biopsy. The largest lesion was approximately $3 \times 2$ $\times 1.5 \mathrm{~cm}$ and was lined by a thick, fibrotic tissue layer (Fig. 5).

Hematoxylin and eosin ( $\mathrm{H}$ and $\mathrm{E})$ stained sections showed dense collagenous tissue surrounding the osseous trabeculae, and peritrabecular clefting was present (Fig. 6a). Mitosis or atypia was not seen (Fig. 6b). The biopsy result revealed active nonspecific chronic inflammation with fibrosis.

In view of the radiographical and intraoperative findings, the absence of any history of trauma, a low probability of dental infection being the cause (as per endodontic and periodontal examinations), absence of evidence of malignant transformation (confirmed by histological findings) [13-15], the researchers confirmed that the case involved non-specific cystic degeneration in the CFD site. Postoperative healing was uneventful (Figs. 1e and 3c), as was the postsurgical follow-up over 

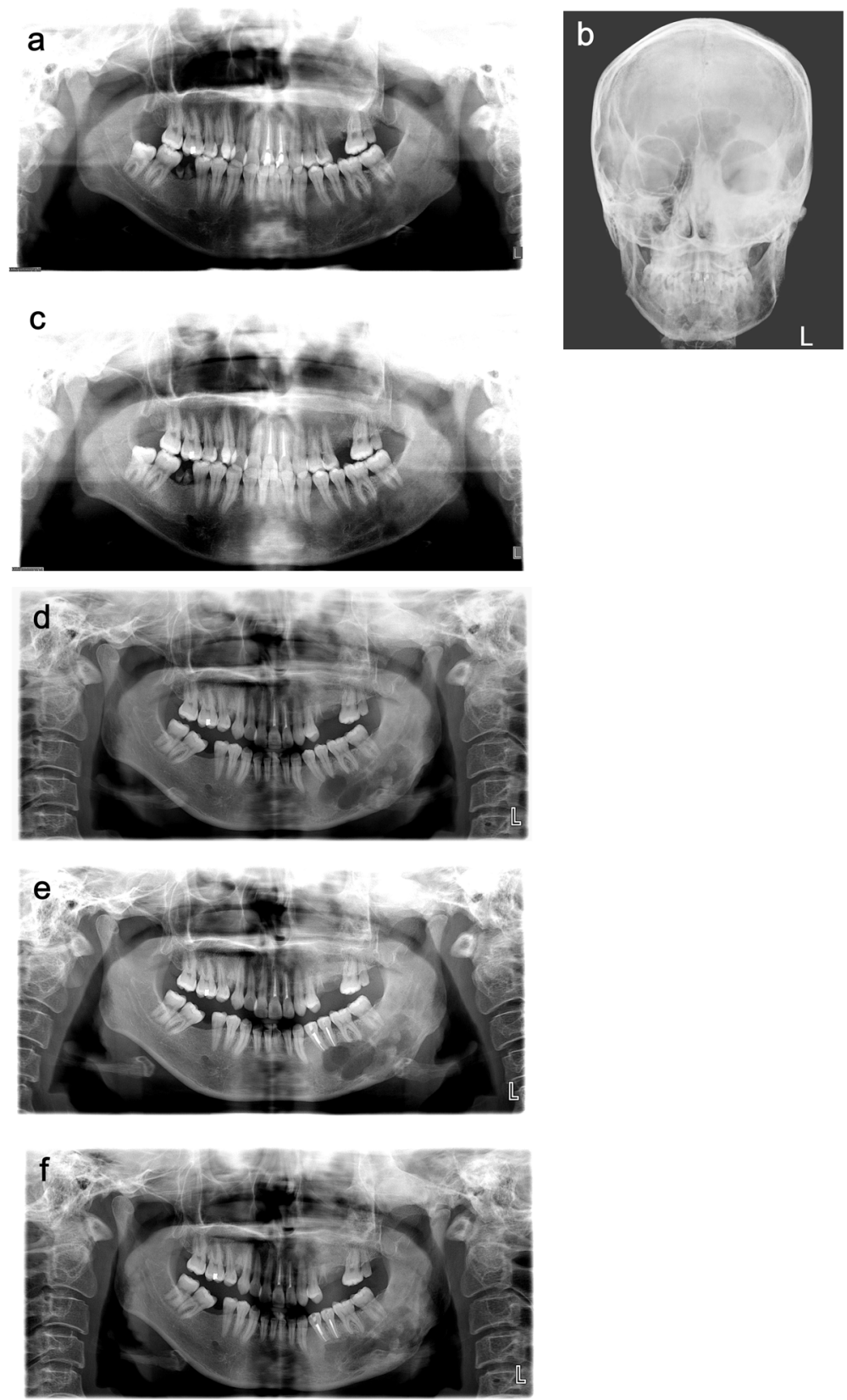

Fig. 1 Radiographic images of the patient's jaw and skull. a Panoramic view of the jaw at baseline taken at the first visit to the out-patient department (2007.5). b Posteroanterior projection (PA) view of the skull at baseline taken at the first visit to the out-patient department (2007.5). c Postoperative panoramic view of the jaw taken 18 months post-surgery (2008.11). d Panoramic view of the jaw taken at the out-patient department (2018.11). e Panoramic view of the jaw after cyst enucleation of the left mandibular lesion. $\mathbf{f}$ Postoperative panoramic view of the jaw 6 months after the surgery in November 2018 (2019.5)

a 6-month period (Figs. 1f and 3d). Thereafter, the patient was lost to follow-up.

\section{Discussion}

The FD cysts with nonepithelial lining have different histological characteristics, in which some are aneurysmal bone cysts, whereas others are simple bone cysts or nonspecific cyst degenerations [6]. The former two entities are characterized by cavities in bones filled with blood and lined by a layer of thick fibrous tissue [8]. Aneurysmal and simple bone cysts are sometimes considered as secondary phenomena of many benign and malignant bone tumors and tumor-like lesions. On the other hand, a lesion that does not have histological features of either an aneurysmal or a simple bone cyst is regarded as nonspecific cyst degeneration [8]. 

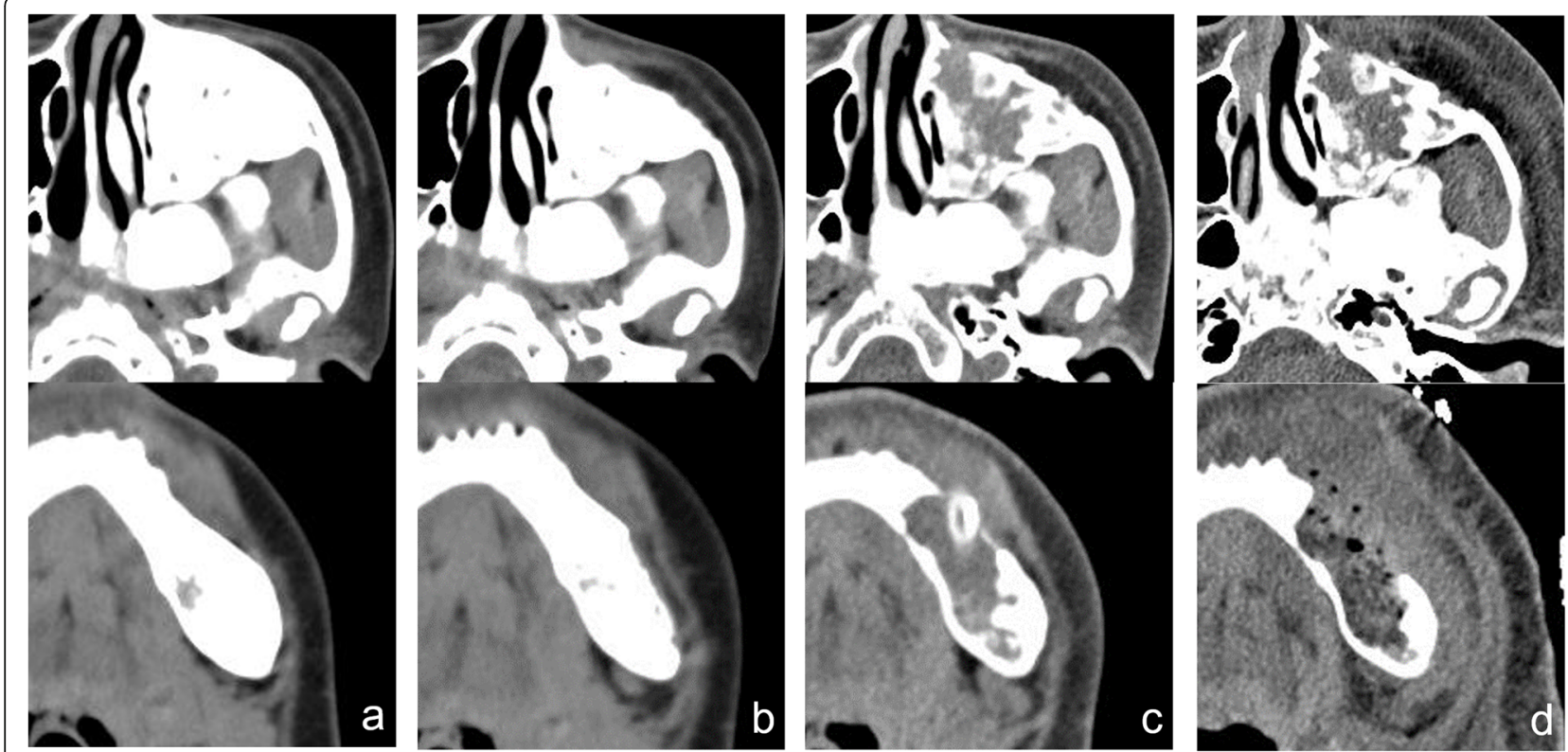

Fig. 2 Contrast-enhanced facial computed tomography (CECT) images of the patient. a CECT image taken at the first visit to the out-patient department (2007.5). b CECT image taken 3 months postoperatively (2007.8). c CECT image after incisional biopsy and marsupialization (2018.11). d Postoperative CECT image after cyst enucleation on the left mandible in November 2018

Cystic degeneration of CFD is most often found in the sphenoid and frontal bones of patients with FD. Pressure from the cysts on the optic nerves can cause acute optic nerve compression in patients with acute cystic degeneration (ACD) of CFD [16]. Cysts tend to show a more aggressive course, which may be due to their association with several potential mechanisms, rather than being determined by a single pathogenetic event. Some cysts are thought to be caused by disruption of venous diploic channels, while it has also been suggested that bone
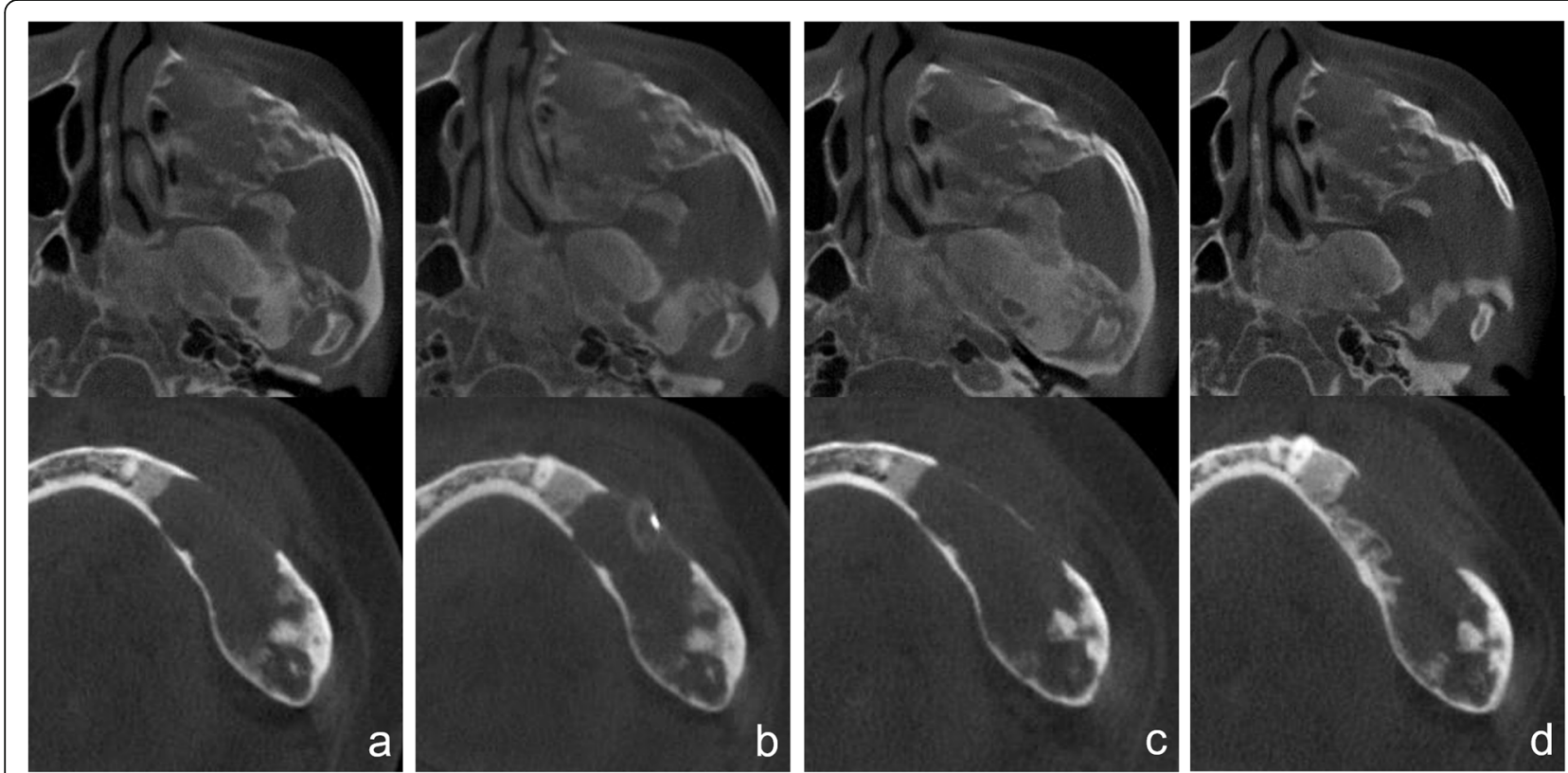

Fig. 3 Cone-beam computed tomography (CBCT) images of the patient. a CBCT image taken at the out-patient department in November 2018. b CBCT image 3 weeks after marsupialization on the left mandible. c Postoperative CBCT image after cyst enucleation on the left mandible in November 2018. d CBCT image taken 6 months after the surgery in November 2018 (2019.5) 


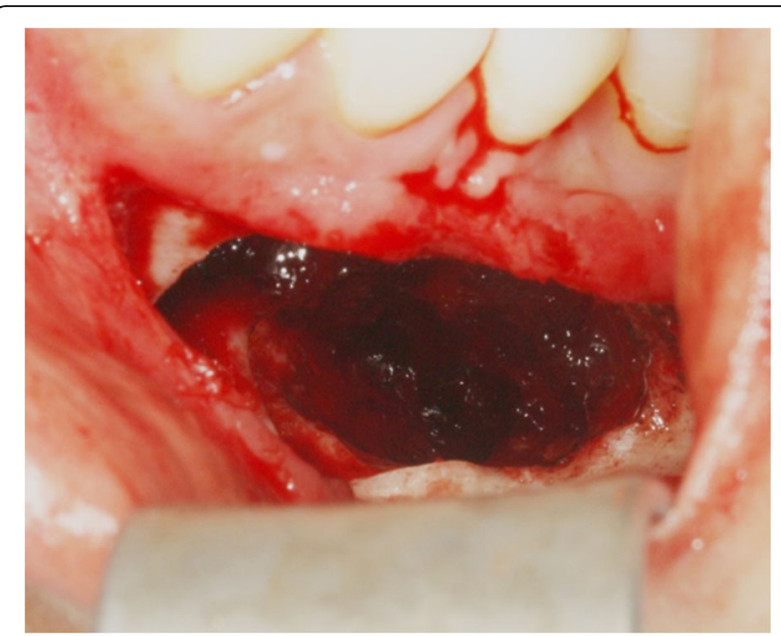

Fig. 4 Intraoperative photograph of the left mandibular lesion after cyst enucleation

cysts may occur due to an intraosseous vascular defect causing intramedullary hemorrhage [17]. Cysts may expand rapidly depending on the site of onset, and can present with a variety of symptoms [8]. Sudden expansion due to the development of cystic degeneration may lead to sudden deterioration of vision [17]. The patient in our case report also presented with cystic degeneration of FD in the maxilla, but did not complain of vision deterioration.

According to the National Institutes of Health cohort study (unpublished observations), cystic degeneration occurred in approximately $5 \%$ of all patients with FD [17], whereas Bahk et al. reported that it occurred in approximately $8 \%$ of all patients [18]. Ferretti et al.

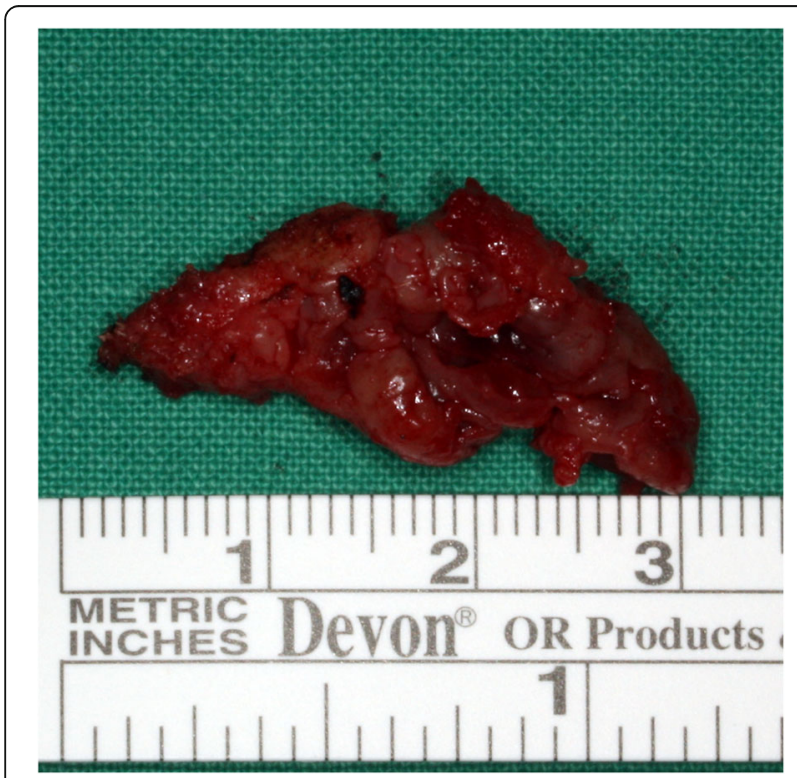

Fig. 5 Photograph of the main mass
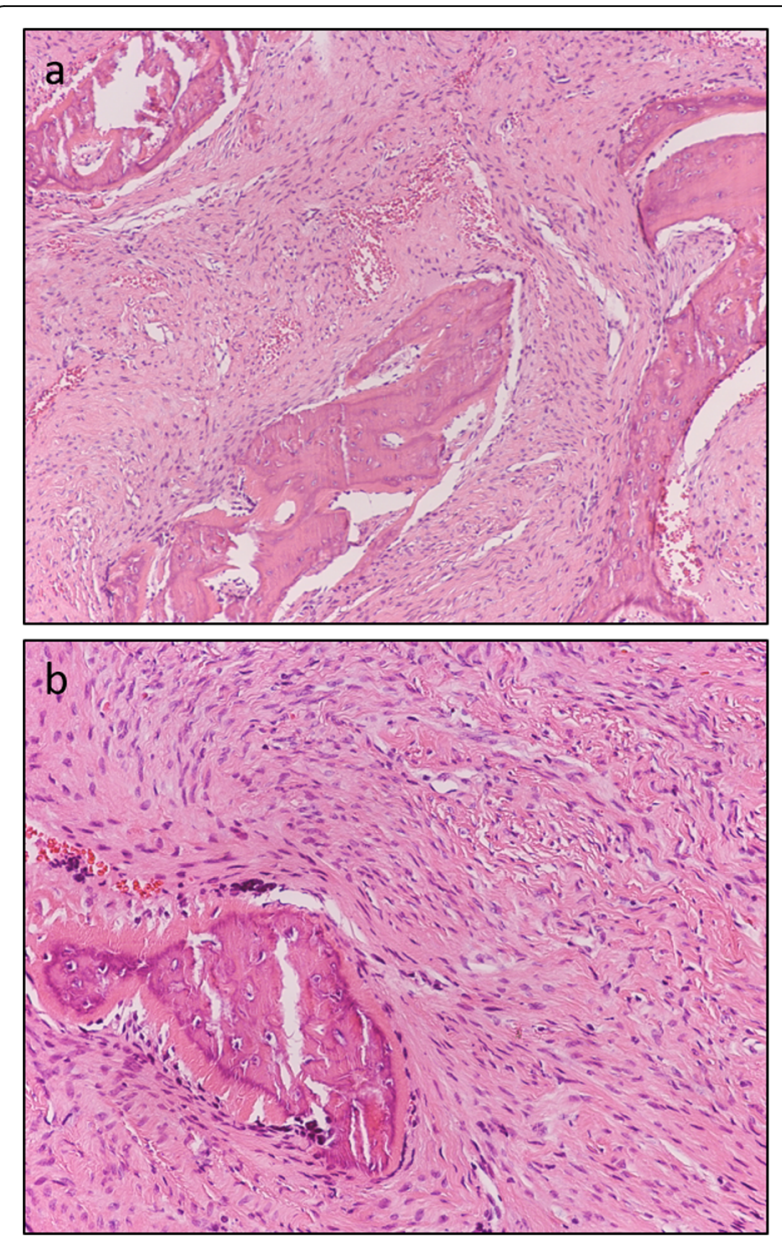

Fig. 6 Histologic features of the mass. a Dense collagenous tissue surrounds the osseous trabeculae and peritrabecular clefting is present $(H$ and $E$ stain, original magnification: $\times 100)$. b Mitosis or atypia is not seen ( $H$ and $E$ stain, original magnification: $\times 200$ )

estimated that cystic degeneration of FD covers the spectrum between a simple bone cyst and an aneurysmal bone cyst [6]. The important clinical feature of cystic degeneration of FD is a rapid increase in cyst size. This may be misdiagnosed clinically as an aneurysmal bone cyst, a simple cyst, or even a sarcomatous change of a pre-existing benign bony tumor. Therefore, a high index of suspicion is needed when there is a rapid increase in cyst size, as it may be caused by cystic degeneration in patients with FD [19]. Cystic areas within the involved bone are depicted on computed tomography (CT) scans as hypointensity. Therefore, CT scans should be obtained regularly every year until the lesion is stabilized [17]. Radiation therapy is not recommended for FD cysts due to a high potential for malignant transformation (up to $44 \%$ ) [20].

Cystic degeneration of FD may exhibit a rapid increase in size, which could be misdiagnosed as a malignant transformation. If FD shows a clear lytic appearance or a 
Table 1 Studies that have reported on surgical treatments for cystic degeneration of craniofacial fibrous dysplasia (CFD)

\begin{tabular}{|c|c|c|c|c|c|}
\hline Author & $\begin{array}{l}\text { Onset age } \\
\text { (years), sex }\end{array}$ & $\begin{array}{l}\text { Location of cystic } \\
\text { degeneration of CFD }\end{array}$ & Symptom & $\begin{array}{l}\text { Surgical } \\
\text { treatment }\end{array}$ & Pathology \\
\hline Ferretti et al. [6] & $12, \mathrm{M}$ & Right mandible & Swelling & Enucleation & Benign fibro-osseous lesion \\
\hline Muraoka et al. [7] & $25, F$ & Left maxillary sinus & Swelling & Decompression & Fibrous dysplasia \\
\hline Diah et al. [8] & $12, \mathrm{M}$ & $\begin{array}{l}\text { Right frontal, Sphenoid, } \\
\text { Occipital bone }\end{array}$ & Swelling & Resection & Aneurysmal bone cyst \\
\hline Diah et al. [8] & $22, F$ & Right sphenoid & $\begin{array}{l}\text { Pain, swelling, visual } \\
\text { deterioration }\end{array}$ & Resection & $\begin{array}{l}\text { Walled, with chronic inflammation } \\
\text { and hemorrhage }\end{array}$ \\
\hline Nadaf et al. [9] & $40, F$ & Both mandible & Swelling & Resection & Fibro-osseous lesion \\
\hline $\begin{array}{l}\text { Oostenbroek- } \\
\text { Bisschop et al. [10] }\end{array}$ & $40, F$ & Right mandibular condyle & Pain & Resection & $\begin{array}{l}\text { Fibrous dysplasia with cystic } \\
\text { degeneration }\end{array}$ \\
\hline Saxena et al. [11] & $9, M$ & Left ethmoid air cells area & $\begin{array}{l}\text { Swelling, left nasal blockage } \\
\text { and bleeding }\end{array}$ & Resection & $\begin{array}{l}\text { Fibrous dysplasia with } \\
\text { hemorrhagic cystic change }\end{array}$ \\
\hline Holl et al. [12] & $16, F$ & Left sphenoid & Visual deterioration & Decompression & Aneurysmal bone cyst \\
\hline Bowers et al. [26] & $24, F$ & Sphenoid & Visual deterioration & Decompression & Data does not exist \\
\hline
\end{tabular}

rapid increase in size, the possibility of cystic degeneration or malignant transformation should be considered. Cystic degeneration of FD that shows an aggressive pattern on radiological findings tends to have poorly defined borders, osteolytic changes, and erosion of the cortex with periosteal reaction. This pattern is similar to that of the malignant transformation of FD [21], making it difficult to differentiate between cystic degeneration and malignant transformation of FD based on radiological findings alone [22]. To avoid unnecessary surgery, a preoperative biopsy should always be conducted [23].

Surgical treatment for FD is limited to cases involving esthetic or functional problems. It is recommended when FD poses a threat to important anatomical structures, such as the eyes or the optic nerves, causes significant esthetic deformities, or if severe pain is clearly associated with the FD process [24]. In some cases, cosmetic trimming of excess bone may be required [11, 25]. Some studies that have reported on surgical treatments for cystic degeneration of CFD are presented in Table 1.

In this case, our patient had a rare case of cystic degeneration simultaneously in the maxillary and mandibular FD. The mandibular lesion showed discomfort and pain, and cyst enucleation was performed. However, follow-up was decided on the maxillary lesions because of the absence of pain or discomfort in that region. We found no noticeable differences in maxillary lesions on CBCT at 6 months follow-up (Fig. 3d). The postoperative site in the left mandible showed progressive bony healing without evidence of recurrence or an increase in lesion size (Figs. 1f and 3d). However, this was a shortterm follow-up. Continuous follow-up is required for judgment of prognosis in the long term.

\section{Conclusions}

Cystic degeneration in CFD cases is rare; cystic degeneration appearing in both the maxilla and mandible is even rarer. In this case, our patient had a rare case of nonspecific cystic degeneration simultaneously in the maxillary and mandibular FD. The mandibular lesion caused discomfort and pain, and cyst enucleation was performed. Continuous follow-up is required for long-term prediction of prognosis.

\section{Abbreviations \\ ACD: Acute cystic degeneration; CBCT: Cone beam computed tomography; CECT: Contrast-enhanced computed tomography; CFD: Craniofacial fibrous dysplasia; CT: Computed tomography; EPT: Electric pulp test; FD: Fibrous dysplasia; MAS: McCune-Albright syndrome}

\section{Acknowledgements \\ We would like to thank Editage (www.editage.co.kr) for English language editing.}

\section{Authors' contributions}

ISH wrote the manuscript. DCK, DHL, and BJA helped in the drafting of the manuscript. SOK contributed to the direction and design of the research and contributed to the review of the paper. All authors read and approved the final manuscript.

\section{Funding}

This research received no specific grant from any funding agency in the public, commercial, or not-for-profit sectors.

\section{Availability of data and materials \\ Not applicable}

\section{Ethics approval and consent to participate}

This study was approved by the Institutional Review Board of Chonbuk National University Hospital (IRB No. CUH 2019-11-043).

\section{Consent for publication}

Written informed consent was obtained from the patient for the publication of this report and any accompanying images.

Competing interests

The authors declare that they have no competing interests. 
Received: 4 February 2020 Accepted: 30 August 2020

Published online: 16 September 2020

\section{References}

1. Menon S, Venkatswamy S, Ramu V, Banu K, Ehtaih S, Kashyap VM (2013) Craniofacial fibrous dysplasia: surgery and literature review. Ann Maxillofac Surg 3:66-71. https://doi.org/10.4103/2231-0746.110088

2. Weinstein LS, Chen M, Liu J (2002) Gs(alpha) mutations and imprinting defects in human disease. Ann N Y Acad Sci 968:173-197. https://doi.org/10. 1111/j.1749-6632.2002.tb04335.x

3. Feller L, Wood NH, Khammissa RA, Lemmer J, Raubenheimer EJ (2009) The nature of fibrous dysplasia. Head Face Med 5:22. https://doi.org/10.1186/ 1746-160X-5-22

4. Panda NK, Parida PK, Sharma R, Jain A, Bapuraj JR (2007) A clinicoradiologic analysis of symptomatic craniofacial fibro-osseous lesions. Otolaryngol Head Neck Surg 136:928-933. https://doi.org/10.1016/j.otohns.2007.01.031

5. Lustig LR, Holliday MJ, McCarthy EF, Nager GT (2001) Fibrous dysplasia involving the skull base and temporal bone. Arch Otolaryngol Head Neck Surg 127:1239-1247. https://doi.org/10.1001/archotol.127.10.1239

6. Ferretti C, Coleman H, Dent M, Altini M (1999) Cystic degeneration in fibrous dysplasia of the jaws: a case report. Oral Surg Oral Med Oral Pathol Oral Radiol Endod 88:337-342. https://doi.org/10.1016/s1079-2104(99)700399

7. Muraoka H, Ishihara A, Kumagai J (2001) Fibrous dysplasia with cystic appearance in maxillary sinus. Auris Nasus Larynx 28:103-105. https://doi. org/10.1016/s0385-8146(00)00077-8

8. Diah E, Morris DE, Lo L, Chen YR (2007) Cyst degeneration in craniofacial fibrous dysplasia: clinical presentation and management. J Neurosurg 107: 504-508. https://doi.org/10.3171/JNS-07/09/0504

9. Nadaf A, Radhika M, Paremala K, Srinath N (2013) Monostostic fibrous dysplasia with nonspecific cystic degeneration: a case report and review of literature. J Oral Maxillofac Pathol 17:274-280. https://doi.org/10.4103/0973029X.119765

10. Oostenbroek-Bisschop JSLI, Verweij JP, van Merkesteyn JPR (2016) Custom made replacement of the mandibular condyle in a case of fibrous dysplasia with cystic degeneration: a case report. Dent J (Basel) 4:42. https://doi.org/ 10.3390/dj4040042

11. Saxena RK, Varshney S, Singh J, Kaushal A, Bishnu PP (2001) Haemorrhagic cystic sino-nasal fibrous dysplasia. Indian J Otolaryngol Head Neck Surg 53 154-157. https://doi.org/10.1007/BF02991515

12. Holl DC, Hardillo JAU, Dammers R, van der Schroeff MP, van der Lugt A (2018) Cystic degeneration of craniofacial fibrous dysplasia. World Neurosurg 120:159-162. https://doi.org/10.1016/j.wneu.2018.08.175

13. Prado Ribeiro AC, Carlos R, Speight PM, Hunter KD, Santos-Silva AR, de Almeida OP, Vargas PA (2012) Peritrabecular clefting in fibrous dysplasia of the jaws: an important histopathologic feature for differentiating fibrous dysplasia from central ossifying fibroma. Oral Surg Oral Med Oral Pathol Oral Radiol 114:503-508. https://doi.org/10.1016/j.oooo.2012.06.014

14. Bavle RM (2014) Mitosis at a glance. J Oral Maxillofac Pathol 18:S2-S5. https://doi.org/10.4103/0973-029X.141175

15. Matsuda Y, Aida J, Ishikawa N, Takubo K, Ishiwata T, Arai T (2017) Morphological markers of chromosomal instability. In: Larramendy ML and Soloneski S (ed) Chromosomal abnormalities - A hallmark manifestation of genomic instability. InTech, Croatia, p17-25. doi:https://doi.org/10.5772/ 67416

16. Papadopoulos MC, Casey AT, Powell M (1998) Craniofacial fibrous dysplasia complicated by acute, reversible visual loss: report of two cases. $\mathrm{Br} J$ Neurosurg 12:159-161. https://doi.org/10.1080/02688699845320

17. Li P, Zhang ZR, Jiang Y, Xia XD, Wang D, Li XF (2009) MR and CT findings of cyst degeneration of sphenoid bone in McCune-Albright syndrome: a case report. Cases J 2:9376. https://doi.org/10.1186/1757-1626-2-9376

18. Bahk WJ, Kang YK, Rhee SK, Chung YG, Lee AH, Bahk YW (2007) Cystic fibrous dysplasia in the long bone. Orthopedics 30:871-873. https://doi.org/ 10.3928/01477447-20071001-05

19. Gupta A, Mehta VS, Sarkar C (2003) Large cystic fibrous dysplasia of the temporal bone: case report and review of literature. J Clin Neurosci 10:364367. https://doi.org/10.1016/s0967-5868(03)00032-8

20. Slow IN, Friedman EW (1971) Osteogenic sarcoma arising in a preexisting fibrous dysplasia: report of case. J Oral Surg 29(2):126-129
21. Ruggieri $P$, Sim FH, Bond JR, Unni KK (1994) Malignancies in fibrous dysplasia. Cancer 73:1411-1424. https://doi.org/10.1002/10970142(19940301)73:5<1411::aid-cncr2820730516>3.0.c0;2-t

22. Okada K, Yoshida S, Okane K, Sageshima M (2000) Cystic fibrous dysplasia mimicking giant cell tumor: MRI appearance. Skelet Radiol 29:45-48. https:// doi.org/10.1007/s002560050008

23. De lure F, Campanacci L (1995) Clinical and radiographic progression of fibrous dysplasia: cystic change or sarcoma? Description of a clinical case and review of the literature. Chir Organi Mov 80:85-89

24. Udayakumar SIV, Paeng JY, Choi SY, Shin HI, Lee ST, Kwon TG (2018) Orthognathic surgery for patients with fibrous dysplasia involved with dentition. Maxillofac Plast Reconstr Surg 40:37. https://doi.org/10.1186/ s40902-018-0176-y

25. Kang M, Jee YJ, Lee DW, Jung SP, Kim SW, Yang S, Ryu DM (2018) Midfacial degloving approach for management of the maxillary fibrous dysplasia: a case report. Maxillofac Plast Reconstr Surg 40:38. https://doi.org/10.1186/ s40902-018-0177-x

26. Bowers CA, Altay T, Shah L, Couldwell WT (2012) Pregnancy-induced cystic degeneration of fibrous dysplasia. Can J Neurol Sci 39:828-829. https://doi. org/10.1017/s0317167100015687

\section{Publisher's Note}

Springer Nature remains neutral with regard to jurisdictional claims in published maps and institutional affiliations.

\section{Submit your manuscript to a SpringerOpen ${ }^{\circ}$ journal and benefit from:}

- Convenient online submission

Rigorous peer review

- Open access: articles freely available online

High visibility within the field

- Retaining the copyright to your article

Submit your next manuscript at $\boldsymbol{\nabla}$ springeropen.com 